\title{
Recognition in Shape and Form's Characteristics of Japanese \& Vietnamese Traditional Daily Products
}

\author{
Ngo Thi Thu Trang \\ University of Architecture Ho Chi Minh City, Ho Chi Minh City, Vietnam
}

\begin{abstract}
This paper presents the major analyses carried out on shape and form's characteristic database from Japanese and Vietnamese traditional daily products (TDPs). The aim of the research is to recognize the vital specifications representing for a national style by comparing two different countries together. By using Quantification Theory Type III and Cluster analysis, firstly, the analyses were undergone separately for Japanese and then Vietnamese product data in succession so that a view of general direction for each country was caught. The result showing a difference in scale of "Complexity" and "Specification" axis between Japan and Vietnam leads to performance of the analysis done on combine database of the two countries to get a clearer view of correlation between them. However, the biggest difference between the two countries lies in "Form" (Geometric-Organic) axis. Continuously, for studying more deeply into outline of product shape, the main ratios that affect the appearance or gorgeousness of product's outline were taken into account and analyzed. By comparing this result to the previous ones, finally a wider and more detail perspective of Japan and Vietnam shape's specification in a mutual relationship was discovered.
\end{abstract}

Keywords: shape and form, Japan and Vietnam, traditional daily products, national characteristics

\section{Introduction}

Since man has started to make objects, through the struggle with nature, he had to constantly improve them in order to reach to useful forms necessary for his life. In the beginning stages, a form is chosen for its utility and then, later, for both its utility and beauty. With the passage of time, forms were standardized and fixed into regular and constant shapes. The variety of forms available in each life system determined the quality of existence and the influence from nature. "Each form has been a landmark, for in its particular time it expressed man's self-recognition. For the same reason it was also a guidepost to the future" (Iwamiya, Yoshida, \& Gage, 1979, p. 16).

Because of that, studying shapes and forms available in each society will bring about a general view of man's awareness and life style at a special time. With the meaning of finding out the "guidepost" to the future of product design from traditional products, this study is an effort in exploring the characteristics and tendency of shape and form of traditional daily products (TDPs) by comparing between two countries: Japan and Vietnam.

Ngo Thi Thu Trang, Ph.D., Industrial Art Faculty, University of Architecture Ho Chi Minh City, Ho Chi Minh City, Vietnam. 


\section{Form's Characteristic Analysis}

\section{Definition of Analysis Elements}

Samples. The initial source of samples is collected from museum visiting, internet, books, and other literature document. The original amount of samples was around 2,200 for Japan, and 2,000 for Vietnam. However, through considering the content of initial samples and the aims of this investigation, the number of initial samples was reduced to 1,151 samples for Japan and 1,049 ones for Vietnam. This reduction was made by dismissing the samples which have different decoration or color or material but the same in shape. That means only the initial samples with different shapes were chosen to be the final samples for this time's analysis. The reduction is necessary for getting a better result from the analysis.

Table 1

Shape Feature's List and Description

\begin{tabular}{|c|c|c|}
\hline Feature & Description of feature & Characteristic of feature \\
\hline \multirow{4}{*}{ Corner } & \multirow{4}{*}{ Indicating corner types on the intersectional edges of faces } & Sharp \\
\hline & & Small arc \\
\hline & & Large arc \\
\hline & & Bevel \\
\hline \multirow{5}{*}{ Line } & \multirow{5}{*}{ Indicating line types on the surfaces of body } & Straight \\
\hline & & Slight curve \\
\hline & & Big curve \\
\hline & & S-line \\
\hline & & Twisty \\
\hline \multirow{3}{*}{ Volume } & \multirow{3}{*}{ Indicating fatness of overall shape } & Fat \\
\hline & & Medium \\
\hline & & Slim \\
\hline \multirow{3}{*}{ Amount of elements } & \multirow{3}{*}{ Indicating quantity of elements } & Abundant \\
\hline & & Sufficient \\
\hline & & Minimized \\
\hline \multirow{4}{*}{ Overall form } & \multirow{4}{*}{ Indicating the main form of product from general view } & Geometric \\
\hline & & Organic \\
\hline & & Free form \\
\hline & & Imitated \\
\hline \multirow{3}{*}{ Outline } & \multirow{3}{*}{ Indicating outline of the whole product shape with details } & Sophisticate \\
\hline & & Average \\
\hline & & Simple \\
\hline \multirow{2}{*}{ Unity of parts } & \multirow{2}{*}{ Indicating the correlation between forms of parts } & Uniform \\
\hline & & Mix \\
\hline \multirow{2}{*}{ Function } & \multirow{2}{*}{ Indicating functions the product shape offers } & Added function \\
\hline & & Reduced function \\
\hline \multirow{4}{*}{ Horizontal ratio $(*)$} & \multirow{4}{*}{ Indicating ratio between the narrowest and the widest parts in the body of products } & High contrast $(\leq 1 / 4)$ \\
\hline & & Harmony $(1 / 2-1 / 3)$ \\
\hline & & Low contrast $(\geq 1 / 2)$ \\
\hline & & Equivalence $(\approx 1 / 1)$ \\
\hline
\end{tabular}

Notes. $(*)$ See reference in Table 6.

Categories. Categories of the analysis were chosen from the most fundamental features of form that are supposed to cover all aspects of product's forms and be able to make clear the distinction between them at a certain level. The features are: corner, line, volume, amount of elements, overall form, outline, unity of parts, 
function, and horizontal ratio. From those features, the more detail characteristics were determined to get clearer description of product's shape. Table 1 presents all 30 features' characteristics and some of them are illustrated with pictures below.

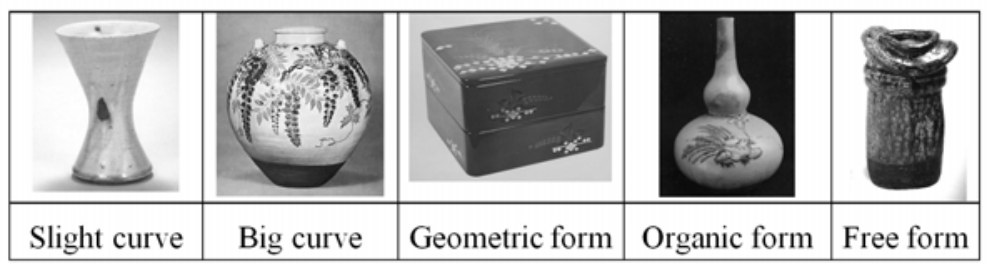

Figure 1. Examples of form's characteristics with illustrations.

\section{Analysis and Result}

From the above mentioned samples and categories, the first database was made. The draft result is presented in the Figure 2. Through the graph, many un-equal points were found in the value of characteristics between Japan and Vietnam. Among that, the most essential points lie in these characteristics: chamber corner, straight line, s-line, minimized element, geometrical shape, free form, reduced function, and equivalent ratio. The importance of these points is either in the difference between values of Japan and Vietnam in each characteristic (e.g., "straight line", "s-line", "minimized element", "geometrical form", "equivalent ratio"), or in the too big difference between average value of one characteristic comparing to others (e.g., "chamber corner", "free-form", "reduced function"). These points will make meaning to the result of the final analysis, as we can see later, due to their dismissal in the final analysis. To gain a better result for analysis, according to correlation between categories and axes in analyzing process, some categories was dismissed in Japanese case, and some others in Vietnamese case. The values of these categories were transferred to the closest ones if suitable.

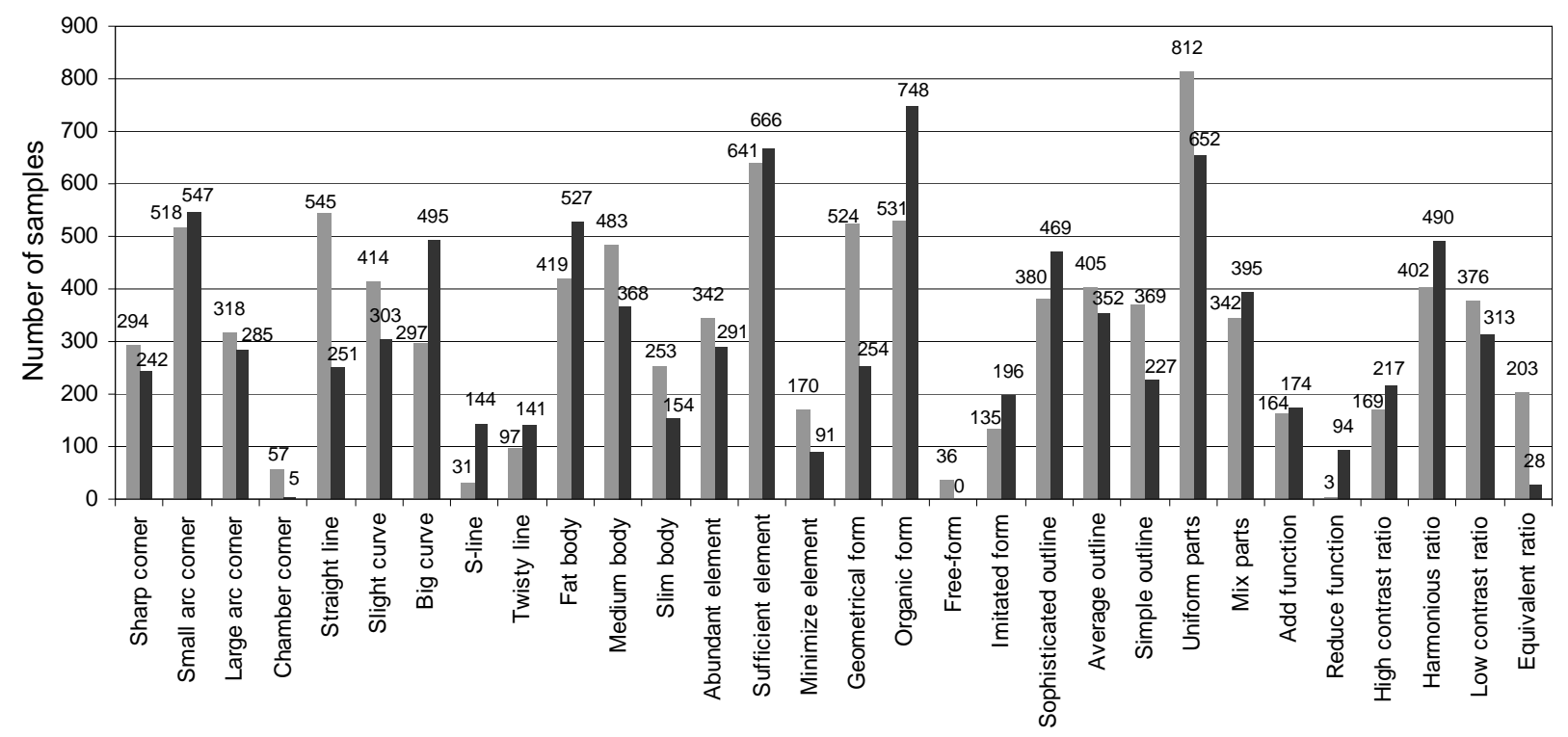

Japan $\square$ Vietnam

Figure 2. Comparing Japanese and Vietnamese database. 
The Table 2 shows the parameters of five axes from Quantification Theory Type III analysis on Japanese samples (Analysis I). And Figures $3 \& 4$ are graphs presenting result from this quantification analysis and cluster analysis.

Table 2

Parameters of Analysis on Japanese Samples

\begin{tabular}{lllll}
\hline Axis No. & Eigen value & Percentage of contribution & Accumulation contribution & Coefficient correlation \\
\hline 1 & 0.265 & $24.3 \%$ & $24.3 \%$ & 0.514 \\
2 & 0.199 & $18.3 \%$ & $42.6 \%$ & 0.446 \\
3 & 0.129 & $11.8 \%$ & $54.4 \%$ & 0.359 \\
4 & 0.117 & $10.8 \%$ & $65.2 \%$ & 0.342 \\
5 & 0.102 & $9.4 \%$ & $74.6 \%$ & 0.320 \\
\hline
\end{tabular}

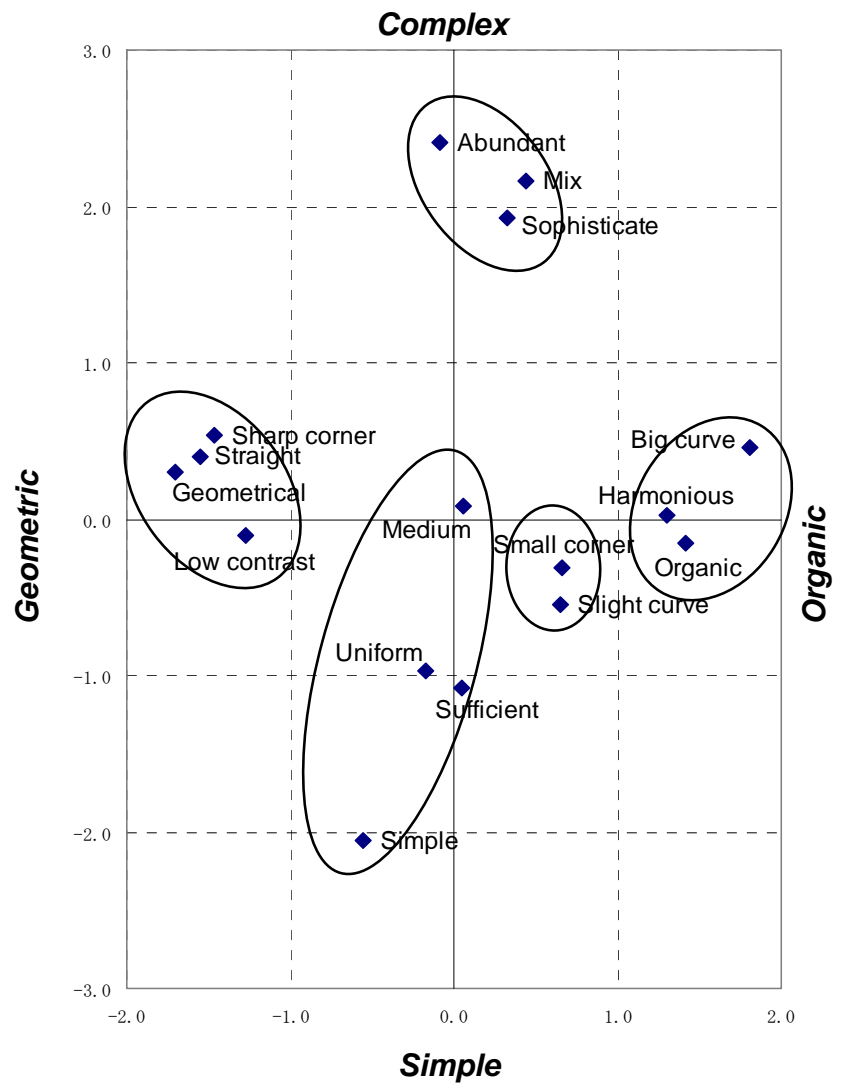

Figure 3. Distribution of form's characteristics of Japanese samples (Axis 1 \& 2). 


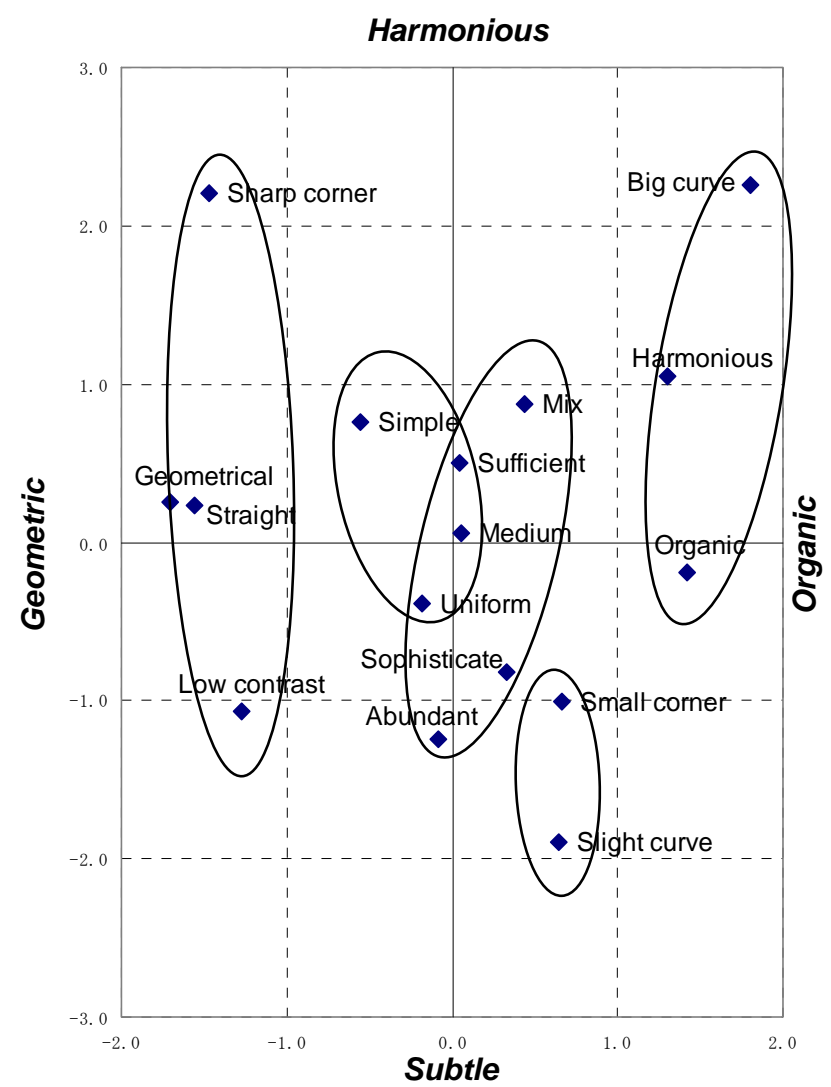

Figure 4. Distribution of form's characteristics of Japanese samples (Axis 1 \& 3).

As the same sequence of above Japanese graphs, the results from analyses for Vietnamese data are presented in the table and graphs below. Table 3 shows the parameters of five axes from analysis on Vietnamese samples (Analysis II). And Figures $5 \& 6$ are graphs of distribution of form's characteristics in Vietnamese traditional daily products.

Table 3

Parameters of Analysis on Vietnamnese Samples

\begin{tabular}{lllll}
\hline Axis No. & Eigen value & Percentage of contribution & Accumulation contribution & Coefficient correlation \\
\hline 1 & 0.186 & $15.8 \%$ & $15.8 \%$ & 0.431 \\
2 & 0.168 & $14.2 \%$ & $30.1 \%$ & 0.409 \\
3 & 0.150 & $12.7 \%$ & $42.8 \%$ & 0.387 \\
4 & 0.137 & $11.6 \%$ & $54.4 \%$ & 0.370 \\
5 & 0.129 & $11.0 \%$ & $65.4 \%$ & 0.360 \\
\hline
\end{tabular}




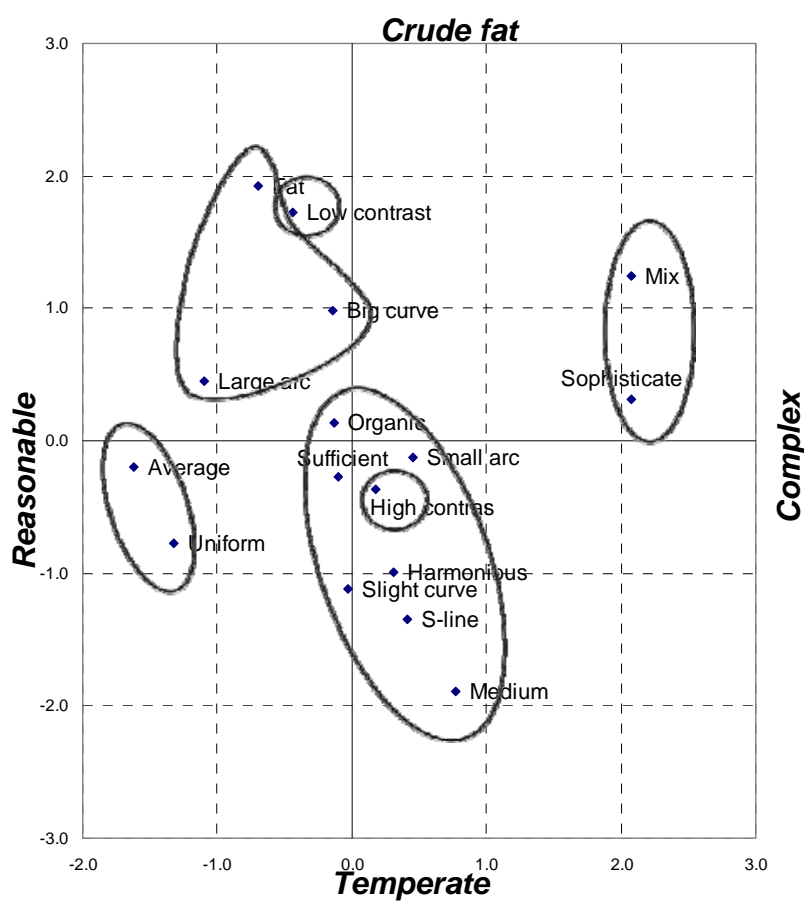

Figure 5. Distribution of form's characteristics of Vietnamese samples (Axis 1 \& 2).

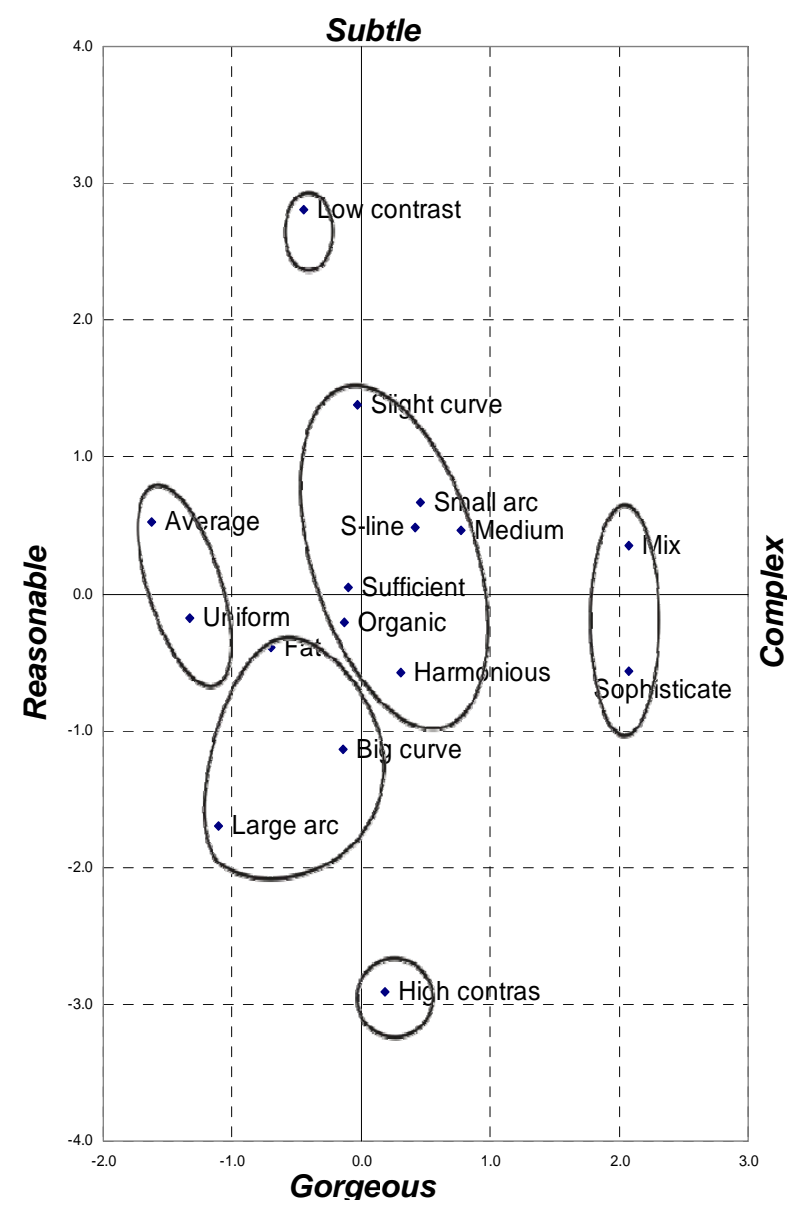

Figure 6. Distribution of form's characteristics of Vietnamese samples (Axis 1 \& 3). 
Table 4

Summary of Axes of Japan and Vietnam

\begin{tabular}{lll}
\hline Axis & Japan (JP) & Vietnam (VN) \\
\hline 1 & Organic-Geometric (Form) & Complex-Reasonable (Complexity) \\
2 & Complex-Simple (Complexity) & Crude fat-Temperate (Volume) \\
3 & Harmonious-Subtle (Specification) & Subtle-Gorgeous (Specification) \\
\hline
\end{tabular}

From the distribution of characteristics in these graphs, meanings of the three main axes were read as following names for Vietnamese categories:

- Axis 1: Complex-Reasonable (Complexity);

- Axis 2: Crude fat-Temperate (Volume);

- Axis 3: Subtle-Gorgeous (Specification).

Once the meaning of axes has been clear, the similarity and dissimilarity is be able to found between the two countries. At first, the similarities are embodied in the two axes: Complexity and Specification. Nevertheless, despite of the same name of axes, the levels in them are slightly different as portrayed in Figure 7. As we can see, the two ends of Japanese axis seem to be higher contrast in Complexity, on the other hand, Vietnamese Specification axis seems to be wider. However, the main difference lies in the axes: Form (Organic-Geometric) of Japan and Volume (Crude fat-Temperate) of Vietnam. Actually, in Specification axis of Vietnam, Crude fat and Temperate describe the characteristics of Organic form.
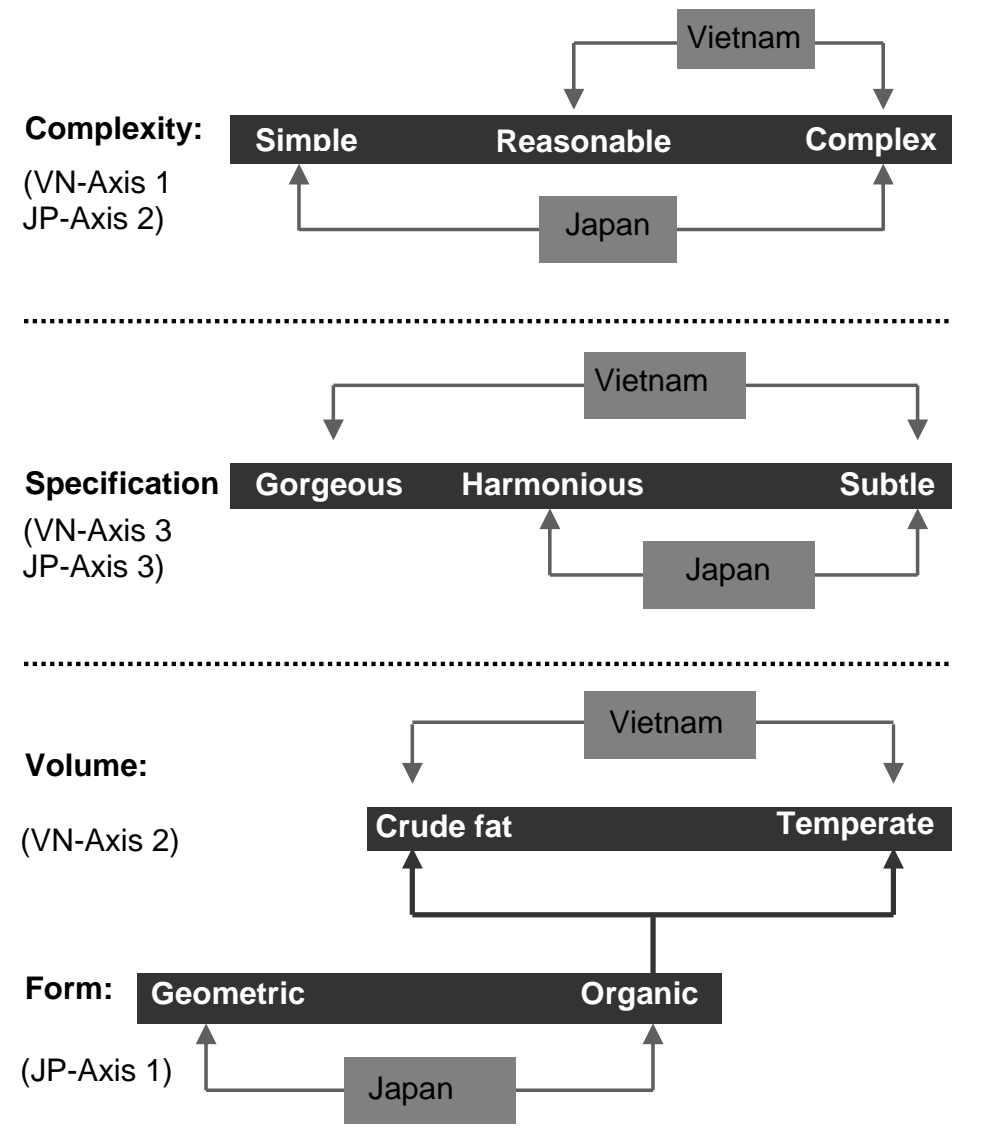

Figure 7. Comparing axes of Vietnam and Japan. 
Due to what was found in comparing results from analyzing data of Japan and then Vietnam, the difference within the width of axes between the two countries leads to the need of checking position of each country in a same space. For that reason, a further Quantification Theory Type III analysis was carried out on the data of both countries combined together (Analysis III). The categories in this analysis were kept the same as the ones appeared in the results of the separated analyses of each country.

The parameters and distribution of shape's characteristics of Japan-Vietnam were respectively shown in Table 5, Figures 8 and 9.

Table 5

Parameters of Analysis on Japan-Vietnam Samples

\begin{tabular}{lllll}
\hline Axis No. & Eigen value & Percentage of contribution & Accumulation contribution & Coefficient correlation \\
\hline 1 & 0.227 & $15.1 \%$ & $15.1 \%$ & 0.476 \\
2 & 0.187 & $12.4 \%$ & $27.5 \%$ & 0.432 \\
3 & 0.148 & $9.9 \%$ & $37.4 \%$ & 0.385 \\
4 & 0.137 & $9.1 \%$ & $46.5 \%$ & 0.370 \\
5 & 0.127 & $8.4 \%$ & $54.9 \%$ & 0.356 \\
\hline
\end{tabular}

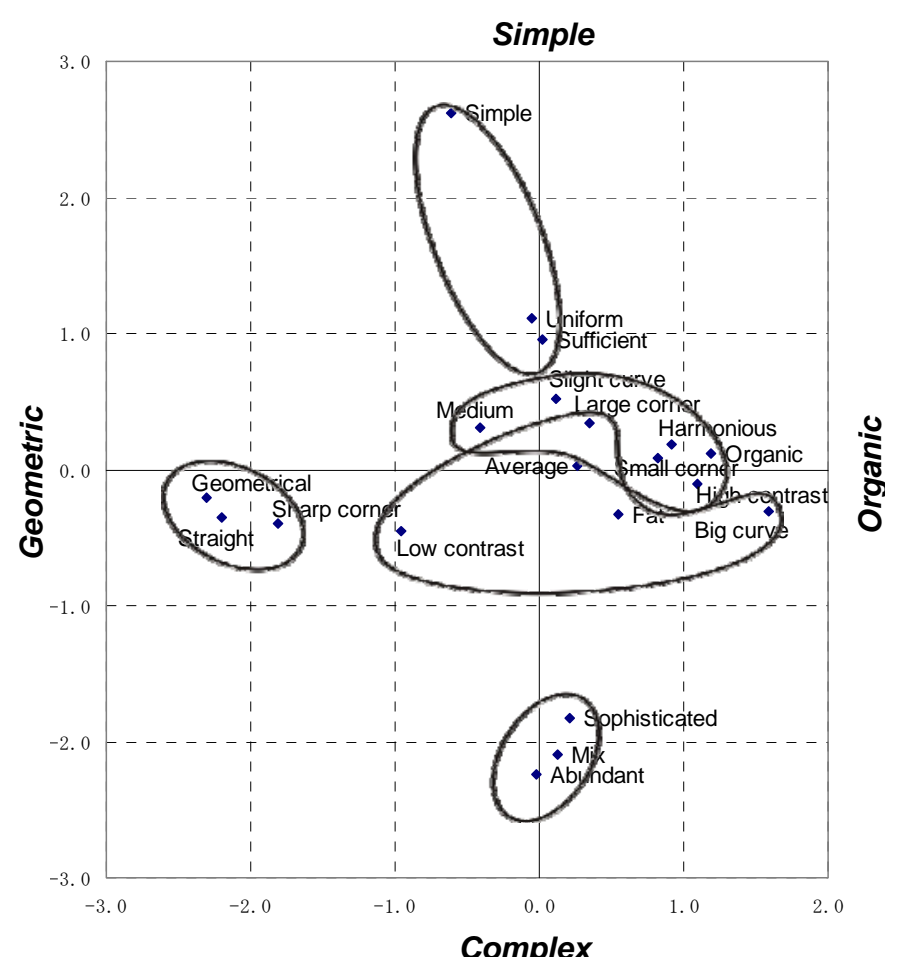

Figure 8. Distribution of shape's characteristics of both Japanese \& Vietnamese samples (Axis 1 \& 2). 


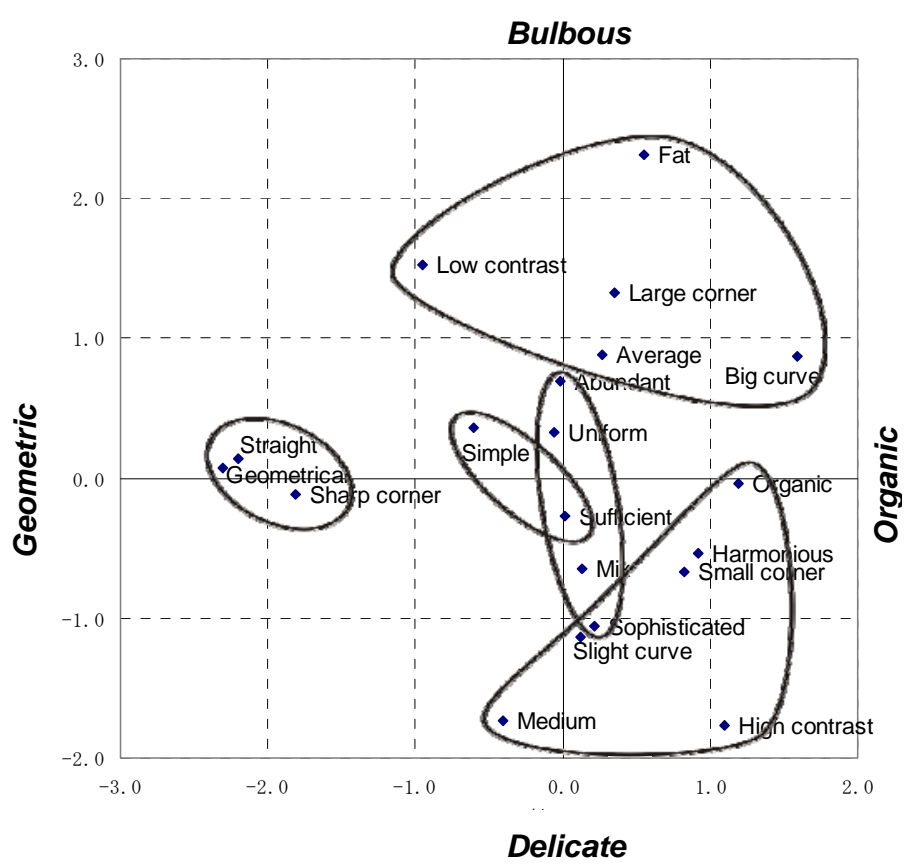

Figure 9. Distribution of shape's characteristics of both Japanese \& Vietnamese samples (Axis 1 \& 3).

And the result was gained with the meanings of three axes as following:

- Axis 1: Organic-Geometric (Form);

- Axis 2: Simple-Complex (Complexity);

- Axis 3: Bulbous-Delicate (Specification).

Continuously, Figures 10 and 11 show the distribution of clusters of both Japanese \& Vietnamese samples. However, due to the over number of samples (Japan $[1,151]+$ Vietnam $[1,049]=2,200$ samples), only clusters that include single (or over $80 \%$ of) Japanese or Vietnamese samples are presented in these graphs. Therefore, these clusters are supposed to be the special points of each country, which are not overlapped by the other. For that, the distribution of these clusters can represent for the special direction of the whole samples.

In Figure 10, we can see a quite clear separation between Japanese and Vietnamese clusters: The Japanese clusters situate near "Simple" and "Geometric" ends, while the Vietnamese ones are close to "Complex" and "Organic" ends. The same in Figure 11, the distinction between Japanese and Vietnamese clusters up to "Simple" and "Geometric" ends is still clear, while quite vague to the "Bulbous-Delicate" axis. This result helps to make clearer for Complexity and Form axis of the previous results (Figure 7) from separated analyses of each country. Combining these results, we have the diagram below (Figure 12). 


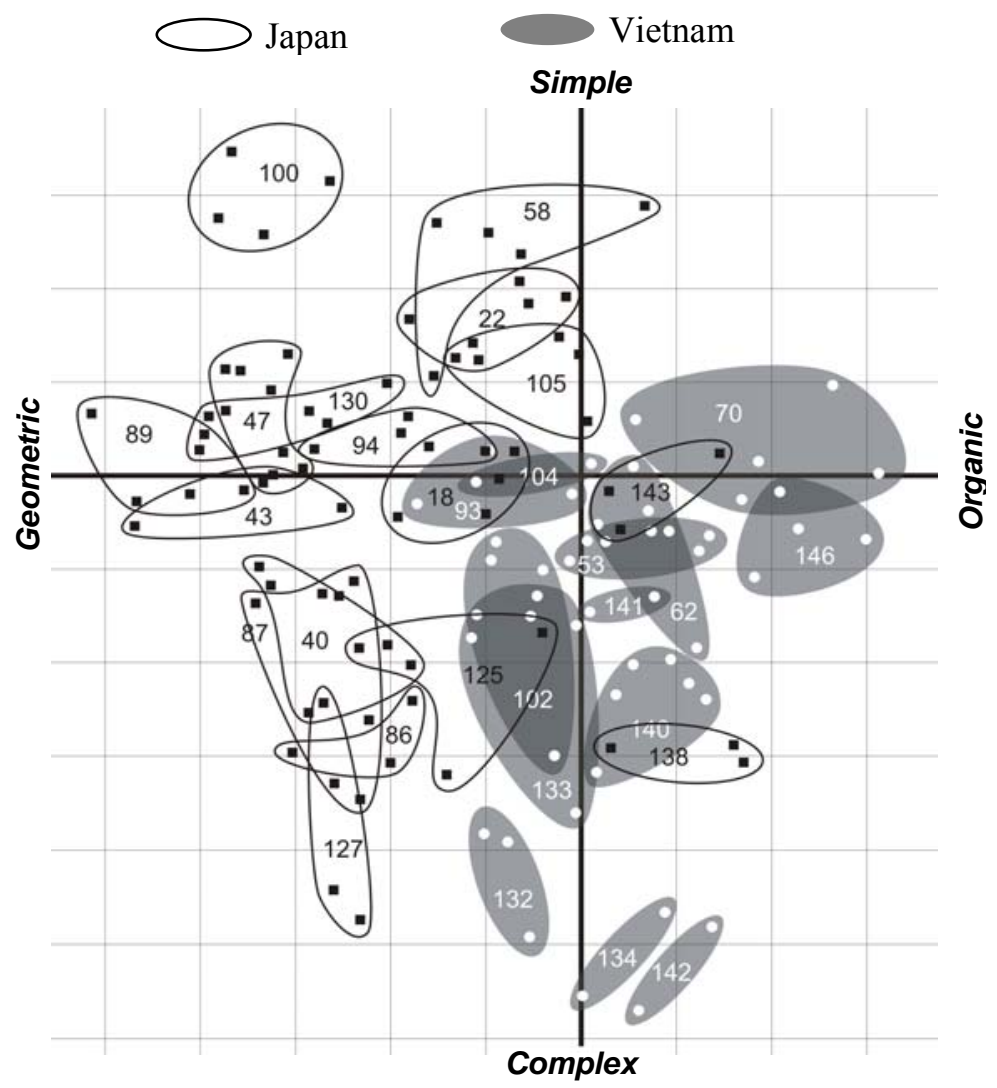

Figure 10. Distribution of clusters of both Japanese \& Vietnamese samples (Axis 1 \& 2).

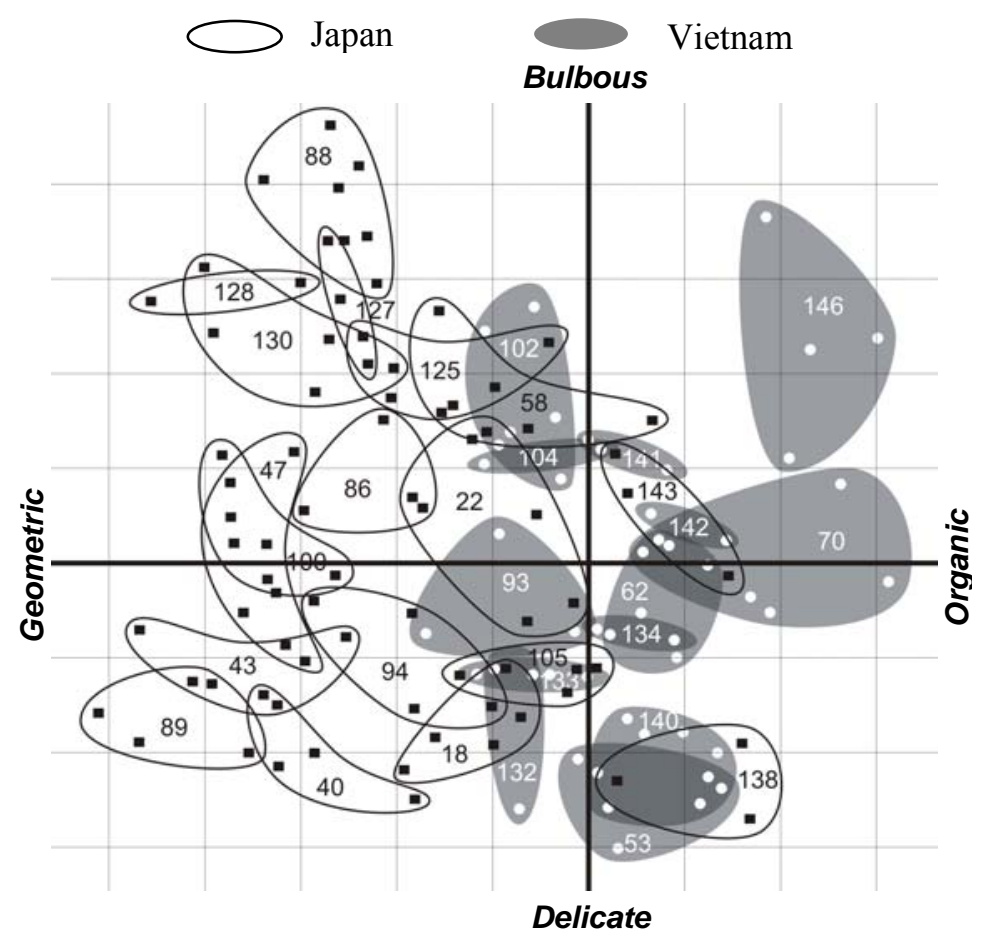

Figure 11. Distribution of clusters of both Japanese \& Vietnamese samples (Axis 1 \& 3). 


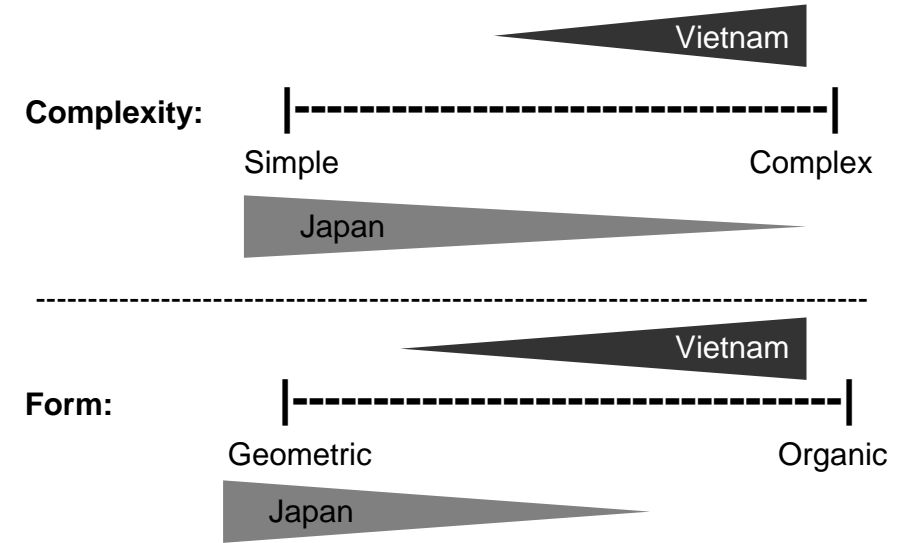

Figure 12. Comparing axes of Japan and Vietnam through results of Analysis III.

From this, it is realized that Vietnamese shapes have a tendency toward Complex and Organic characteristics, while Japanese, oppositely, toward Simple and Geometric ones. Nevertheless, Specification axis still implies a wondering. And this problem is aimed to be solved in the next part of the study, analysis on ratios.

\section{Analysis on Ratios}

Although "Horizontal ratio" has been in the category list of the Analysis I (see Table 1), that just one type of ratios implies in a product's form. In this part, the objective is to study more detail in the main ratios that strongly affect the attractive appearance of object's shape. In other word, this part of research went deeply into analyzing the gorgeousness or specification of products' outline.

\section{Definition of Analysis' Elements and Method}

The samples used for this analysis are the same with the ones in the form's characteristic analysis. Both samples of Japan and Vietnam were examined not separately but together. The main ratios that were chosen for category are called Horizontal Ratio, Vertical Ratio, and Overall Ratio. All these ratios are described with illustration in the Table 6. Because ratio is quantitative data, the method chosen for this investigation was Principle Component Analysis.

Table 6

Category of Ratio's Analysis

\begin{tabular}{|l|l|l|l|}
\hline Type & Horizontal Ratio $(\mathrm{a} / \mathrm{b})$ & Vertical Ratio (c/d) & Overall Ratio (x/y) \\
\hline Description & $\begin{array}{l}\text { Indicating ratio between the width of } \\
\text { the narrowest and widest parts of } \\
\text { object's body }\end{array}$ & $\begin{array}{l}\text { Indicating ratio between the height of } \\
\text { main parts of object's body }\end{array}$ & $\begin{array}{l}\text { Indicating ratio between the height } \\
\text { and width of the whole object's } \\
\text { shape }\end{array}$ \\
\hline Illustration
\end{tabular}




\section{Process and Result}

The parameters and results of Principle Component Analysis on ratios of Japanese and Vietnamese product's shape are respectively shown in the Tables $7 \& 8$ and Figure 13.

Table 7

Total Variance Explained

\begin{tabular}{llll}
\hline \multirow{2}{*}{ Component } & \multicolumn{3}{c}{ Initial eigenvalues } \\
\cline { 2 - 4 } & Total & \% of variance & Cumulative \% \\
\hline 1 & 1.400 & 46.657 & 46.657 \\
2 & 1.000 & 33.327 & 79.984 \\
3 & 0.600 & 20.016 & 100.000 \\
\hline
\end{tabular}

Table 8

Component Matrix

\begin{tabular}{lll}
\hline & \multicolumn{2}{c}{ Component } \\
\cline { 2 - 3 } & 1 & 2 \\
\hline Horizontal Ratio & 0.808 & 0.260 \\
Vertical Ratio & 0.836 & 0.001 \\
Overall Ratio & -0.218 & 0.965 \\
\hline
\end{tabular}

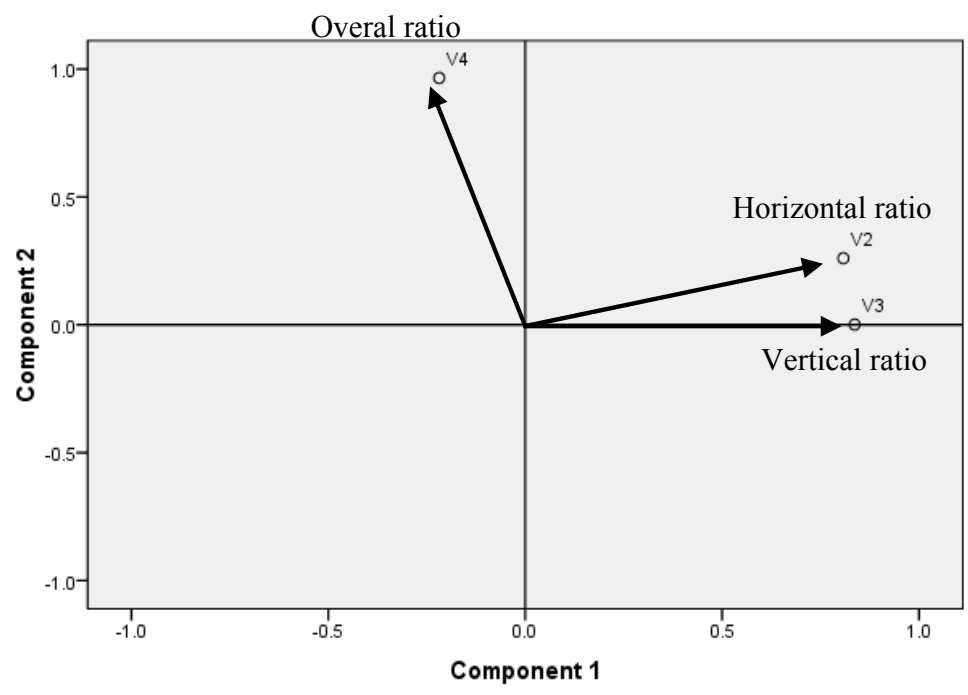

Figure 13. Component plot.

By using Principle Component Analysis method, two components were extracted, which are named as General Ratio (including Overall Ratio) and Detail Ratio (including Horizontal and Vertical Ratios). Figures 14 $\& 15$ are separated plots of Japanese and Vietnamese samples' score from the analysis. 

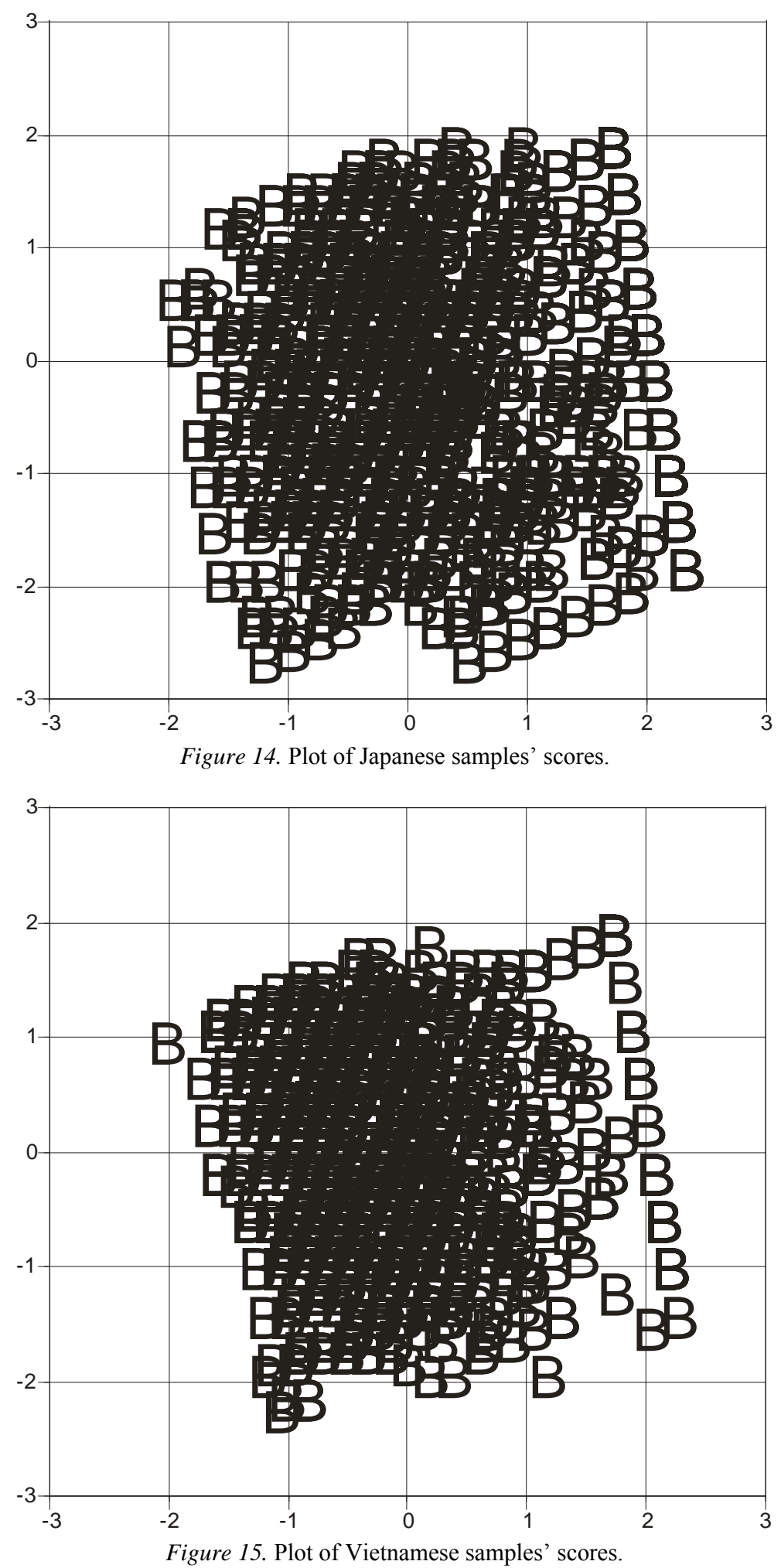

By combining component plot (Figure 13) and sample score plots (Figures 14, 15 in turn), we have graphs for Japan and Vietnam in Figures 16 and 17 respectively. In those graphs, for easier comparison, the density of sample distribution was translated into gray scales: dark value present for high density, light value for low 
density. The ratios have values from 0.1 to 1.0 (for simplicity, only one decimal number was taken). In vectors of ratios (Figure 13), "1.0" end means equivalence, then the opposite end is understood as high contrast. In Figures 16 \& 17, O means Overall Ratio, H is Horizontal Ratio, and V is Vertical Ratio.

Through comparing the two graphs, it can be recognized that, in general, the distribution of Japanese sample scores is wider than Vietnamese one. Considering the number of Japanese samples and Vietnamese samples are fairly equal, the distribution shown in the graphs means Japanese product's shapes are more diversity while Vietnamese ones are more condensed.

In detail, if looking at area near H-Equivalence and V-Equivalence, the density of Vietnamese sample score distribution is very dilute, even some places are almost clear. Whereas Japanese one is still condensed at this area, although the level of density is slightly lower other areas. This can be understood as the shapes with V-Equivalence and H-Equivalence are not popular in Vietnamese products. As illustrated in the Figure 18, the shapes with V-Equivalence and H-Equivalence are likely to be geometrical. This result one more time confirms the outcome of the last investigation on shape's characteristics.

Figure 18 is the combination of Figures 16 and 17 with product's shapes illustrating for ratios around the graphs. Through Figure 18, it is obvious that Japanese sample distribution expands more widely comparing to Vietnamese one at the area between V-High contrast, H-High contrast, and O-High contrast. Whilst, Vietnamese sample distribution is protrusive little bit at the corner of V-High contrast, H-High contrast, and O-Equivalence. Through the illustrated shapes around the graph, we can see that the high contrast of ratios yields attractiveness or gorgeousness of shape. Then the shapes with V-High contrast, H-High contrast, and O-High contrast will be at the highest level of gorgeousness which is named as Distinctive Level. And the shapes with H-Equivalence, V-Equivalence, and O-Equivalence will be at the lowest level of gorgeousness which is named as Equivalent Level.

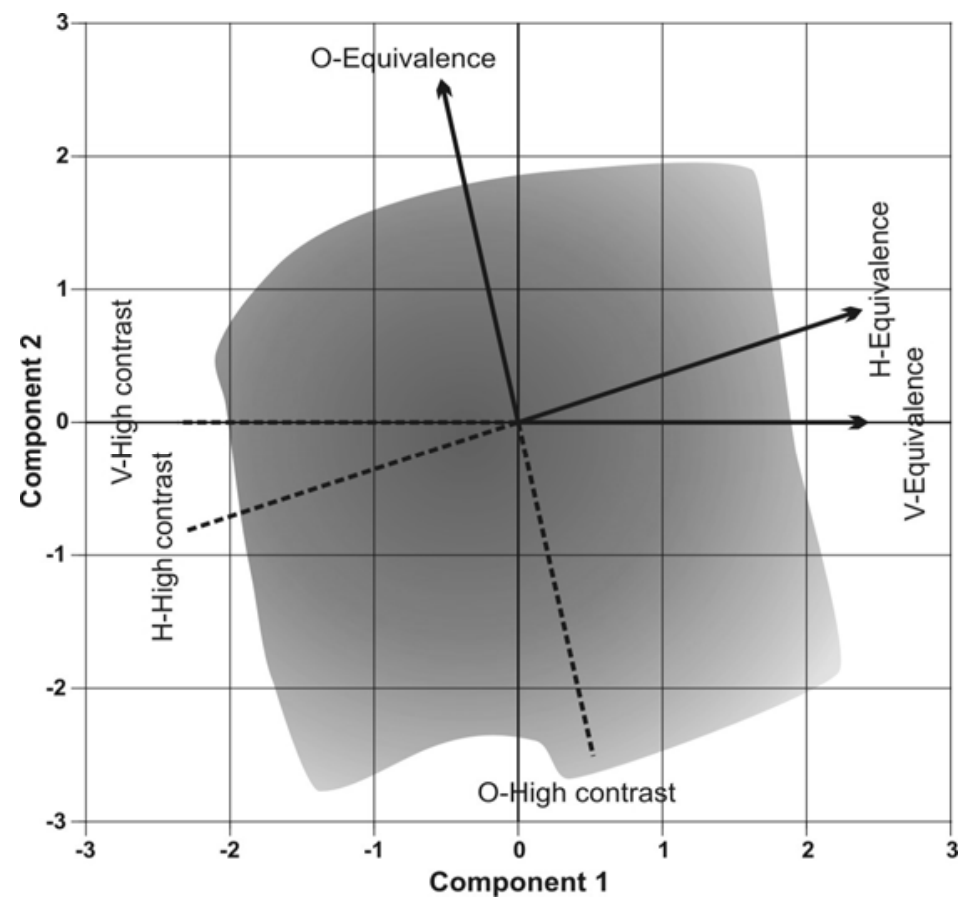

Figure 16. Graph result of Japan. 


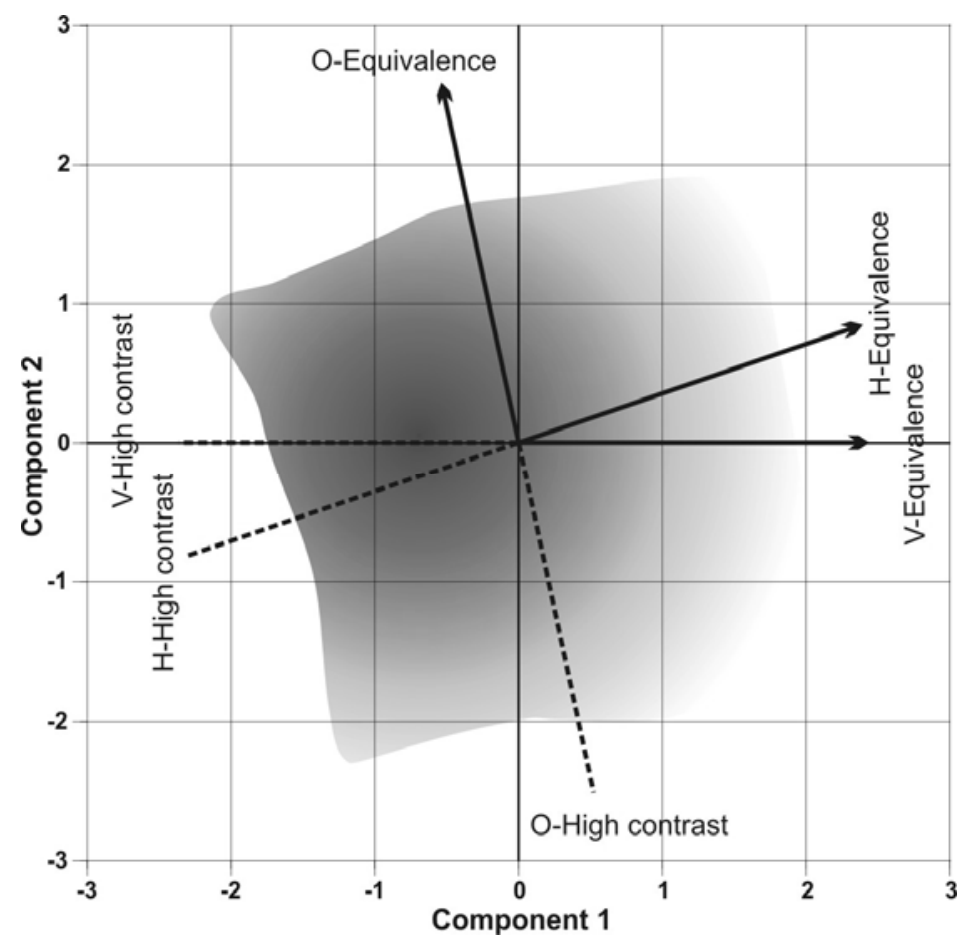

Figure 17. Graph result of Vietnam.

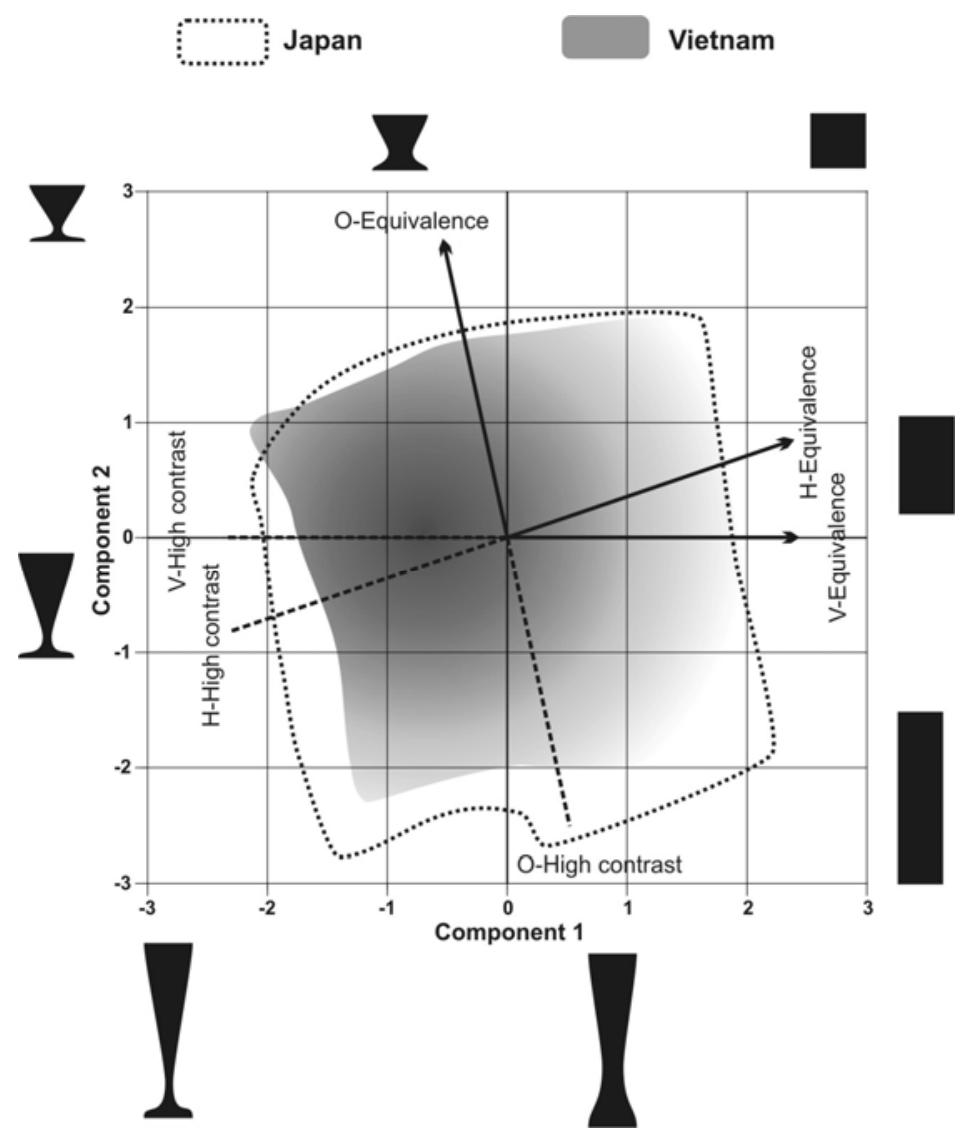

Figure 18. Graph result of Japan and Vietnam. 
As the same way, if dividing the gorgeousness scale into five levels as shown in the Figure 19, the range of Vietnamese shapes concentrate at the middle of the scale, while Japanese ones quite stretch out from the highest to the lowest level.

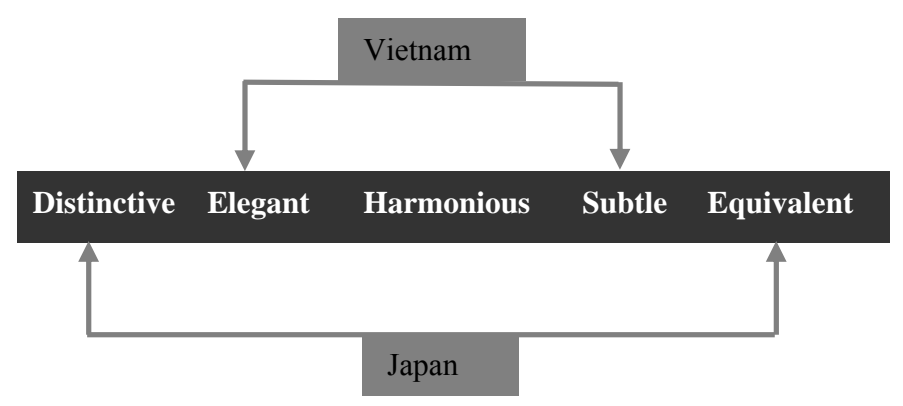

Figure 19. Graph result of Japan and Vietnam.

Comparing this result to the Specification axis of the previous result (Figure 7), we see a difference here: In ratio analysis' result, Japanese scale is wider than Vietnamese one; in contrast, the Specification axis of the previous result shows that Japanese scale is narrower.

The explanation for this difference can be drawn from the scope of the analysis methods. In the analysis on shape's characteristics, some weak categories were dismissed to gain the final strongest axis's meaning. This means the Specification axis in the previous result (Figure 6) just shows the direction of the most common shape's group. Meanwhile, the ratio analysis took into account almost every case without cutting off. Then the result of ratio analysis reveals a wider scope. From this, we can think that Japanese shapes stretch out from Distinctive to Balance characteristic (although the products with Distinctive and Balance shape are not much), whereas Vietnamese ones more strongly concentrate in the middle levels (Elegant or Harmonious) of the characteristic's scale.

\section{Conclusion}

The outcome of form's characteristic Analysis I of this study using Quantification Theory Type III method reveals the dissimilarity between Japanese and Vietnamese traditional daily products. Japanese product's forms spread from the freely unsymmetrical form to rigid geometric ones, whereas Vietnamese products mostly concentrate on various styles of organic forms. Moreover, although the main axes of complexity and volume were found in both countries, the difference embodies in the scale of each axis. The Analysis II done on combining data of both Japanese and Vietnamese shape's characteristic helped to make clearer about direction of each country in a mutual correlation. It is a tendency of Japan toward geometric and simple direction, and Vietnam toward organic and complex ones. The analyses on ratio elements were deep digs into specification or gorgeousness of product's shape. The results of ratio analyses showed that Japanese shape's gorgeousness seems to stretch out from lowest level-balance to the highest levels-distinction comparing to the emphasis in harmonious levels of Vietnamese case. Therefore, the Equivalent (equivalence in all three main ratios) shapes and Distinctive (high contrast in all three main ratios) shapes are the special ones of Japanese traditional daily products. 
To understand the general way of thinking of a country in creating shape and form of objects is not simple. All the possibilities that might reveal the sensitive points were taken into account with the attempt of catching the most vital spirit in shape and form's creation and selection. Furthermore, the method of comparing results from two different countries brings about a clearer view or recognition of what is the important national characteristics of each country.

From the outcome of this research, looking back to what is found in the previous investigation on employment of materials (Trang, 2009), we can see a link going through the characteristics of using materials and creating shape for traditional daily products in each country. It is the favorite in employing highly contrasted styles in Japanese making object comparing to the harmony styles of Vietnamese traditional daily products.

\section{References}

Becker, J. (1986). Karatsu ware: A tradition of diversity. Tokyo, New York: Kodansha International.

Iwamiya, T., Yoshida, M., \& Gage, R. L. (1979). Forms, textures, images: Traditional Japanese craftsmanship in everyday life. New York, Tokyo: Weatherhill.

Le, P. H., Chien, N. D., \& Ngoc, N. Q. (1995). Bat Trang ceramics, 14th-19th centuries. Hanoi: World Publisher.

Noma, S. (1978). Photographs by Takahashi Bin: The arts of Japan. (J. Rosenfield, Trans. and Adapted). Tokyo, New York: Kodansha International.

Successive generations of beauty Nakamura sect Satoru house of lacquer. (2003). Kyoto: Tankosha.

Trang, N. T. T. (2009). Comparative analysis on employment of materials in Japanese and Vietnamese traditional daily products. Bulletin of Japanese Society for Science of Design, 56(3), 31-40.

1200 years of Japanese pottery: Suntory collection: From Nara Sansai, Imari and Nabeshima ware through Ninsei and Kenzan. (2003). Tokyo: Suntory Art Museum. 